\title{
A CASE OF PALATAL PERFORATION CAUSED BY TOXOPLASMOSIS
}

\author{
Christine Katusiime ${ }^{1}, M B C h B, P G D P P M$ \\ Ponsiano Ocama ${ }^{2}, M B C h B, M M e d$ \\ Andrew Kambugu ${ }^{1}$, $M B$ ChB, MMed \\ ${ }^{I}$ Makerere University, College of Health Sciences, Infectious Diseases Institute, Kampala, Uganda \\ ${ }^{2}$ Makerere University, College of Health Sciences, Department of Medicine, Kampala, Uganda
}

We describe the case of a 35-year-old HIV-positive man seen at the Infectious Diseases Institute, Kampala, Uganda, with a 2-week history of palatal perforation.

HIV infection has several oral manifestations, including oral candidiasis and oral hairy leucoplakia. Occasionally unusual presentations requiring rigorous investigations are seen, and in these cases the diagnosis sometimes remains a dilemma owing to limited investigation facilities. ${ }^{1-3}$ We present the case of a patient who presented with a puzzling oral lesion.

\section{CASE HISTORY}

A 35-year-old HIV-positive man first presented to the Infectious Diseases Institute, Kampala, in 2006. He had World Health Organization (WHO) stage IV disease with a history of oesophageal candidiasis, a baseline weight of $58 \mathrm{~kg}$ and a CD4+ count of 56 cells/ $/ \mu \mathrm{l}$. He was initiated on highly active antiretroviral therapy (HAART) using a combination of stavudine, lamivudine and nevirapine (Triomune-30) together with cotrimoxazole prophylaxis.

Six months after initiating ART, a follow-up CD4+ count had risen to 226 cells/ $/ \mu$. Subsequently the count rose to $298 \mathrm{cells} / \mu \mathrm{l}$.

In September 2008, the patient presented with a 4-month history of drenching night sweats and high-grade fevers, his temperature being recorded as $39.3^{\circ} \mathrm{C}$ and $39.7^{\circ} \mathrm{C}$ on two occasions. There was no history of cough, weight loss or loss of appetite. The results of investigations at this time were as follows: full blood count - leucocytopenia, $1.1 \times 10^{3} / \mathrm{l}$; ESR $25 \mathrm{~mm} / \mathrm{h}$; blood slide for malaria parasites - none seen; urinalysis - normal; chest radiograph - normal; abdominal ultrasound scan - hepatosplenomegaly with a suggestion of a haemangioma in the liver; serum cryptococcal antigen - negative; blood cultures - no bacterial growth after 7 days of incubation; TPHA non-reactive.
On the basis of the unrelenting fever the patient was started on tuberculosis (TB) treatment consisting of rifampicin, isoniazid, ethambutol and pyrazinamide. During this time his antiretroviral therapy was switched to zidovudine, lamivudine and efavirenz.

Two weeks after the start of TB treatment, the patient developed drug-induced hepatotoxicity and the TB treatment was stopped. A week later difficulty in swallowing and marked weight loss were noted. He was treated with fluconazole and acyclovir for a month with no improvement, at which time he was admitted.

Two months after stopping TB medication the liver enzymes stabilised and he was restarted on anti-TB medication.

In January 2009, the patient presented with a 3-week history of high-grade fever, loss of appetite, cervical lymphadenopathy and a 2-week history of pus discharge from a palatal perforation, which was treated with ceftriaxone and fluconazole (Fig. 1).

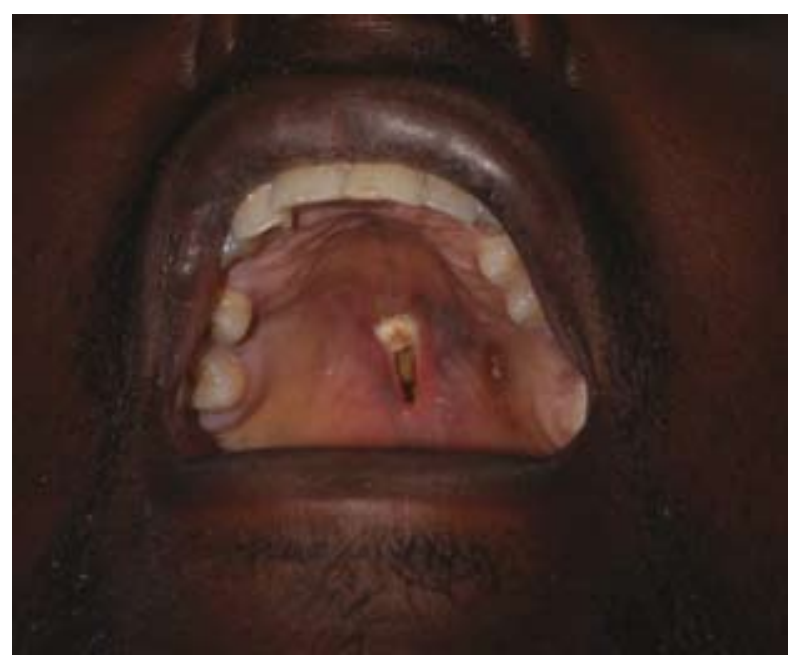

Fig. 1. Perforation of hard palate. 
An ENT consultation gave a presumptive diagnosis of histoplasmosis and the patient was initiated on amphotericin B.

The results of investigations at this stage were as follows: oral fistula swab $-2+$ yeast cells, $2+$ Gram-positive cocci and 3+ Gram-negative rods; no inflammatory cells seen. A complete blood count showed macrocytosis and mean corpuscular volume of $103 \mathrm{fl}$; CD $4+$ count (13 January) - 71 cells/ $\mu$ l (this was less than half the peak CD4+ count, prompting measurement of viral load to exclude immunological failure); viral load (13 January) - not detected, with a lower limit of detection of 400 copies; lymph node aspirate - polymorphonuclear leucocytes 3+, Gramnegative rods 2+, Gram-positive cocci 1+, no acidand alcohol-fast bacilli seen, Escherichia coli isolated; lymph node biopsy - fibrosis and chronic granulomatous inflammation with central necrosis and epitheloid cells, small organisms with halo extracellular and withinmacrophage cytoplasm. Morphological features were consistent with toxoplasma lymphadenitis (Fig. 2).

The patient did not return to the Institute. The first follow-up phone call (within a week) revealed that he was deteriorating and was too weak to come to the clinic, and when we called the next week we were told that he had died. Unfortunately, the histopathology results were only obtained after his death.

\section{DISCUSSION}

This case is an example of the rare oral lesions seen in HIV-infected patients in our clinic. We comprehensively reviewed the literature on bone and joint disease in association with HIV infection but did not find a case of toxoplasma-related bone disease. Toxoplasma infection of the oral cavity is uncommon. ${ }^{4} \mathrm{~A}$ case of

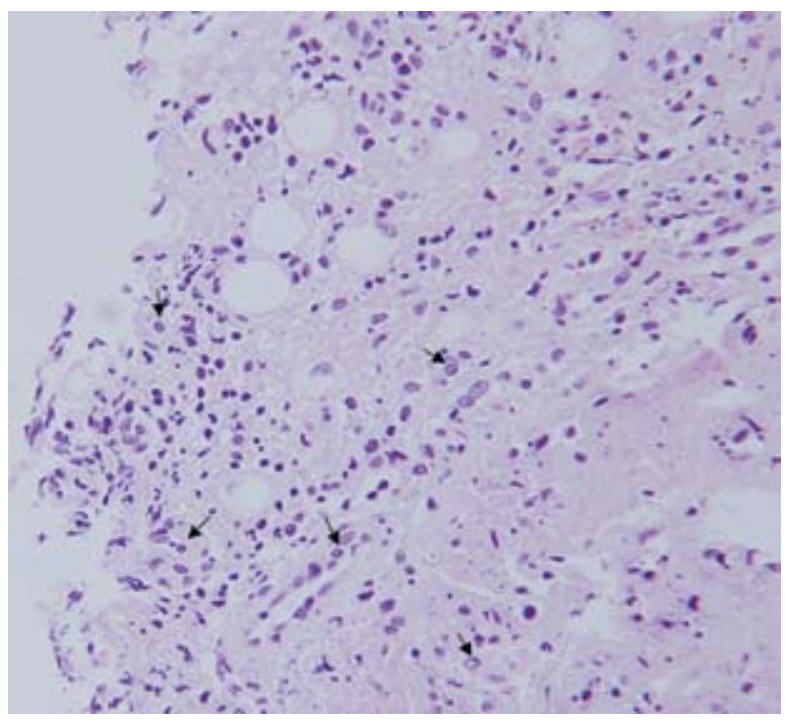

Fig. 2. Intracellular organisms with prominent outlines indicated by arrows.

intra-oral lymphadenitis secondary to toxoplasmosis has however been reported. ${ }^{4}$

In our case defective cell-mediated immunity as a result of immunosuppression may have facilitated the rapid dissemination of toxoplasma, ${ }_{1}^{5}$ resulting in bone invasion causing bone disintegration and destruction. ${ }^{5}$

Acknowledgement: Dr Robert Lukande, Histo-pathologist, College of Health Sciences, Makerere University.

REFERENCES

1. Ficarra G, Shillitoe E. HIV-related infections of the oral cavity. Crit Rev Oral Biol Med 1992; 3(3): 207-231.

2. Ficarra G. Oral lesions of iatrogenic and undefined etiology and neurologic disorders associated with HIV infection. Oral Surg Oral Med Oral Pathol 1992 73(2): 201-211.

3. Penneys N , Hicks B. Unusual cutaneous lesions associated with acquired immunodeficiency syndrome. J Am Acad Dermatol 1985; 13: 845-852.

4. Appel B, Mendelow $H$, Pasqual H. Acquired toxoplasma lymphadenitis. Oral Surg Oral Med Oral Pathol 1979; 47(6): 529-532.

5. Balachandran C, Sabita L, Kanthraj G. Perforation of hard palate in lues maligna associated with HIV infection. Genitourin Med 1997; 73(3): 225.

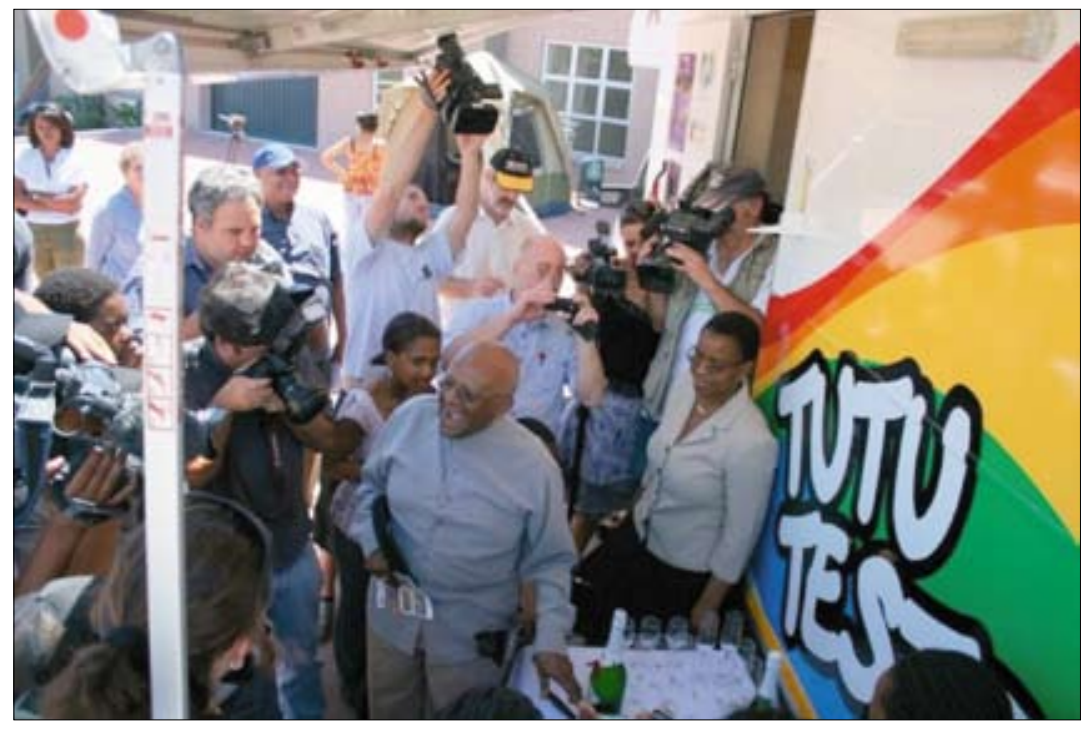

